Article

\title{
Effect of Porous Structure on the Microwave Absorption Capacity of Soft Magnetic Connecting Network $\mathrm{Ni} / \mathrm{Al}_{2} \mathrm{O}_{3} / \mathrm{Ni}$ Film
}

\author{
Hu Wei ${ }^{1, *}$, Li Cheng ${ }^{1}$ and Dmitry Shchukin ${ }^{2}$ \\ 1 College of Materials Science \& Technology, Nanjing University of Aeronautics and Astronautics, \\ Nanjing 210016, China; licheng@nuaa.edu.cn \\ 2 Stephenson Institute for Renewable Energy, Department of Chemistry, University of Liverpool, \\ Chadwick Building, Peach Street, Liverpool L69 7ZF, UK; d.shchukin@liverpool.ac.uk \\ * Correspondence: huwei@nuaa.edu.cn
}

Received: 19 March 2020; Accepted: 8 April 2020; Published: 9 April 2020

\begin{abstract}
Microwave radar absorbing materials have been the focus of the radar stealth research field. In this study, ceramic structured porous honeycomb-like $\mathrm{Al}_{2} \mathrm{O}_{3}$ film was prepared by anodic oxidation, and an $\mathrm{Ni}$ layer was deposited on the $\mathrm{Al}_{2} \mathrm{O}_{3}$ film via electrodeposition in a neutral environment to form a flower- and grain-like structure in a three-dimensional (3D) network $\mathrm{Ni} / \mathrm{Al}_{2} \mathrm{O}_{3} / \mathrm{Ni}$ film. The films both have a through-hole internal structure, soft magnetic properties, and absorb microwaves. The dielectric loss values of two films were little changed, and the maximum microwave absorption values of flower- and grain-like $\mathrm{Ni} / \mathrm{Al}_{2} \mathrm{O}_{3} / \mathrm{Ni}$ film were -45.3 and $-31.05 \mathrm{~dB}$ with relatively wide effective bandwidths, respectively. The porous ceramic structure $\mathrm{Al}_{2} \mathrm{O}_{3}$ interlayer prevented the reunion of $\mathrm{Ni}$ and isolated the eddy current to improve the microwave absorption properties. The material presented in our paper has good microwave absorption performance with a thin thickness, which indicates the potential for lightweight and efficient microwave absorption applications.
\end{abstract}

Keywords: connected network $\mathrm{Ni} / \mathrm{Al}_{2} \mathrm{O}_{3} / \mathrm{Ni}$; soft magnetic properties; microwave absorption

\section{Introduction}

Magnetic overlapping multilayer films formed by alternately depositing ferromagnetic materials on an insulating material substrate have good chemical stability, a tunnel magnetoresistance effect, and a microwave absorption function [1]. The exploration of this artificial nanostructure has broadened the research field of magnetic transmission theory [2,3]. According to the giant magnetoresistance (GMR) in thin film structures composed of alternating ferromagnetic and nonmagnetic layers [4], as adjacent magnetic layers are always separated by non-magnetic layers, the coupling pattern of magnetic moments of adjacent layers usually changes from anti-parallel or disordered arrangement to parallel arrangement under the action of an external magnetic field, which may be caused by a non-magnetic isolation structure or the change in an internal magnetic field. To obtain lightweight, efficient, and stealthy microwave absorption materials, scientists further studied the interaction between microwaves and this kind of nanocomposite [5]. Kang et al. [6] proved that the soft magnetic properties of porous carbon nanotubes significantly improved after filling with ferromagnetic metals.

Other research showed that using $\mathrm{Al}_{2} \mathrm{O}_{3}$ as an insulating layer for magnetic particles can improve the microwave stealth ability of magnetic materials [7]. Eriksson et al. [8] designed a new type of ring parallel plate resonator with excellent microwave absorption performance using the transparent property of the modulated $\mathrm{Cu} / \mathrm{SiO}_{2} / \mathrm{Cu}$ multilayer film. Wei et al. prepared an $\mathrm{Fe}_{3} \mathrm{Al}$ composite using a mechanochemical method and coated $\mathrm{Al}_{2} \mathrm{O}_{3}$ as an insulating layer on the surface of $\mathrm{Fe}_{3} \mathrm{Al}$. The reflectivity value of this $\mathrm{Fe}_{3} \mathrm{Al} / \mathrm{Al}_{2} \mathrm{O}_{3} / \mathrm{Fe}_{3} \mathrm{Al}$ absorbing coating was lower than $-20 \mathrm{~dB}$ in the 
range from 7.2 to $17.4 \mathrm{GHz}$ when the thickness of the $\mathrm{Al}_{2} \mathrm{O}_{3}$ coating was 1.5-2.5 mm [9]. In general, the non-magnetic porous structure of $\mathrm{Al}_{2} \mathrm{O}_{3}$ provides nucleation points for magnetic particles so that the magnetic particles can be highly dispersed. As the material dielectric loss and magnetic loss enhance the microwave attenuation ability, metals can be prepared with $\mathrm{Cr}, \mathrm{Ni}$, or their alloys; while ceramic matrices can also be prepared with sapphire, quartz, $\mathrm{BN}$, and $\mathrm{BeO}$ [10].

Magnetic metal nanoparticles easily agglomerate; the ceramic $\mathrm{Al}_{2} \mathrm{O}_{3}$ network structure acts as an insulator layer inside the metal magnetic medium, which also blocks the eddy current effect and reduces electromagnetic loss. In this paper, a $3 \mathrm{D}$ connected network structured $\mathrm{Ni} / \mathrm{Al}_{2} \mathrm{O}_{3} / \mathrm{Ni}$ film was constructed on the ceramic structure $\mathrm{Al}_{2} \mathrm{O}_{3}$ film via electrodeposition. The $\mathrm{Ni} / \mathrm{Al}_{2} \mathrm{O}_{3} / \mathrm{Ni}$ film has good soft magnetism and microwave absorption properties within a frequency range of 2 to $18 \mathrm{GHz}$. The connected network structure can considerably reduce the density, optimize the impedance matching of films, and avoid the agglomeration of the nanomaterials. Unlike traditional vertical one-dimensional (1D) channel alumina, the 3D staggered pipe structure inside ceramic structured alumina film better isolates the dispersed metal particles and reduces the eddy current effect between the particles [11].

\section{Materials and Methods}

High-purity aluminum foil (Al 99.99\% with a thickness of $200 \mu \mathrm{m}$ ) was cut into $6 \times 6 \mathrm{~cm}^{2}$ rectangle samples and annealed in a tube-type vacuum furnace at $500{ }^{\circ} \mathrm{C}$ for $3 \mathrm{~h}$ in a nitrogen atmosphere. Then, the substrate surface was cleaned in absolute ethyl alcohol under bath ultrasonic treatment for $20 \mathrm{~min}$. Afterward, aluminum samples were introduced into $\mathrm{NaOH} 1 \mathrm{M}$ to clear the surface oxide for $1 \mathrm{~min}$ at $40{ }^{\circ} \mathrm{C}$ and $\mathrm{HNO}_{3} 1 \mathrm{M}$ (to neutralize $\mathrm{OH}^{-}$) for $2 \mathrm{~min}$ at room temperature $\left(25^{\circ} \mathrm{C}\right.$ ). Finally, the samples were washed with distilled water. All the chemicals were of analytical grade and used as purchased. The electrolyte was an equal volume mixture of aqueous $5 \mathrm{wt} \%$ phosphoric acid and $3.6 \mathrm{wt} \%$ oxalic acid, with an aluminum sheet as the anode and tinplate as the cathode. The samples were pretreated for $2 \mathrm{~h}$ under the $50 \mathrm{~V}$ DC voltage at $10^{\circ} \mathrm{C}$, then taken out, washed with distilled water, and soaked into mixed acid (phosphoric acid containing $6 \mathrm{wt} \%$ and chromate $1.8 \mathrm{wt} \%$ ) for $3 \mathrm{~h}$ at $60^{\circ} \mathrm{C}$ to eliminate the irregular oxide layer on the pure $\mathrm{Al}$ substrate. The second anodic oxidation was carried out for $2 \mathrm{~h}$ under the same conditions as the first anodic oxidation, and we obtained an alumina film with a porous ceramic structure.

The samples were used as the working electrode and a platinum electrode as the counter electrode; an electrochemical workstation (CHI 750C, Chenhua, Shanghai, China) was used. The Ni nanoparticles were plated by cyclic voltammetry from a $1 \mathrm{M} \mathrm{NiSO}_{4}$ solution with $\mathrm{pH}$ around 7.2 for $6000 \mathrm{~s}$. Pure (99.99\%) $\mathrm{Al}_{2} \mathrm{O}_{3}$ powder was mixed with the Ni sample using the hydrothermal method $\left(100{ }^{\circ} \mathrm{C}\right)$ for $2 \mathrm{~h}$ on ceramic structured alumina film, followed by annealing at $1000{ }^{\circ} \mathrm{C}$ for $5 \mathrm{~h}$.

The samples' morphology and composition were analyzed by scanning electron microscopy (SEM, Hitachi S-4800, Tokyo, Japan) and energy-dispersive X-ray spectrometer (EDS). The crystal composition of the samples was measured by X-ray diffraction (XRD, scanned from $10^{\circ}$ to $80^{\circ}$ with a step size of $0.02^{\circ}$ and scanning speed $\left.2^{\circ} / \mathrm{min}\right)$ with a $\mathrm{Cu}-\mathrm{K} \alpha$ radiation source $(\lambda=0.154056 \mathrm{~nm})$, and the spectrum was analyzed using Jade 6.0 software (Jade Company, Christchurch, New Zealand). The static magnetic properties of the samples at room temperature were measured using a comprehensive physical properties testing system (PPMS-9, Quantum Design, San Diego, CA, USA) and a vibrating sample magnetometer (VSM, Lakeshore 7407, Columbus, OH, USA). The measured temperature was $25^{\circ} \mathrm{C}$ and the maximum applied magnetic field strength was $10 \mathrm{kOe}$. Using liquid nitrogen $(77 \mathrm{~K})$ as the absorbent, the specific surface area of the compound was measured using an ASAP 20204.01 version instrument (Micromeritics, Norcross, GA, USA), the details of which were: ambient temperature: $22.00^{\circ} \mathrm{C}$; analysis bath temperature: $-195.792{ }^{\circ} \mathrm{C}$; equilibration interval: $10 \mathrm{~s}$; warm free space: $27.9249 \mathrm{~cm}^{3}$; and cold free space: $86.2767 \mathrm{~cm}^{3}$. The electromagnetic microwave properties were measured using the reflection transmission network method using the Microwave Network Analyzer (MNA, HP 8722ES, Xiamen, China) in the frequency range of 2 to $18 \mathrm{GHz}$. The dielectric testing fixture was tested using sweeping 
frequency sweep (Agilent 6453A, Xiamen, China), and the test sample was shaped as a disc with a radius of $5.5 \mathrm{~cm}$ and a thickness of $1.7 \mathrm{~cm}$. The microwave absorbing properties of the pure $\mathrm{Ni} / \mathrm{Al}_{2} \mathrm{O}_{3}$ powder sample was tested after being mixed with $15 \mathrm{vol} \%$ paraffin wax filling.

\section{Results}

The SEM images of the alumina surface after anodic oxidation demonstrated a pore size of around $100 \mathrm{~nm}$ and an interconnection between the pores. This overlapped porous structure is different from the traditional 1D vertical pipe alumina membrane (Figure 1a). The traditional alumina has regular vertical tubes (Figure 1b). Crystals accumulated and grew into many grain-like particles on the film surface, and a small amount of grain-like $\mathrm{Ni} / \mathrm{Al}_{2} \mathrm{O}_{3} / \mathrm{Ni}$ appeared from a holistic perspective (Figure 1c). The surface of $\mathrm{Ni} / \mathrm{Al}_{2} \mathrm{O}_{3} / \mathrm{Ni}$ prepared on the surface of traditional straight pass alumina only formed vertical parallel nickel-plated pipes, in which $\mathrm{Ni}^{2+}$ in the solution was reduced and gradually deposited inside alumina pipelines (Figure 1d). From the top view, the ceramic structure alumina membrane with an internal communication network is composed of many crossing pipelines (Figure 1e) and the interior has a large number of 3D passageways, which resemble many overlapping nets from above. After being oxidized excessively, the tube walls melt and irregular faults form in the vertical direction inside the alumina (Figure 1f) Ni particles deposited outward along the internal channels of the alumina accumulated on the film surface like porous petals. The porous structure was maintained and resembled Ni laces around those holes (Figure 1g). Overall, the deposited Ni piled up like flowers with increasing deposition time (Figure 1h). Microscopic examination indicated that metallic Ni was uniformly deposited on the alumina nanotube.
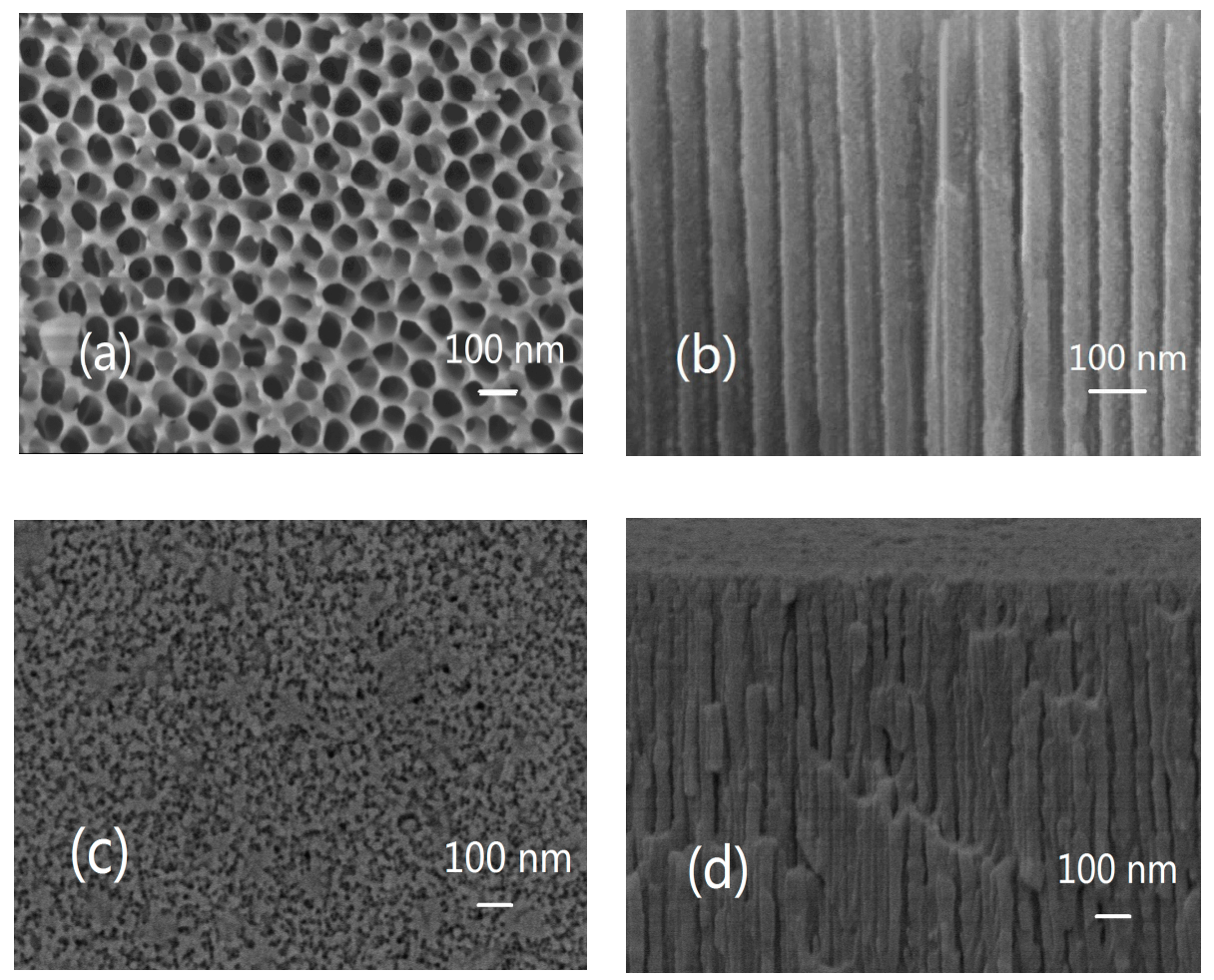

Figure 1. Cont. 

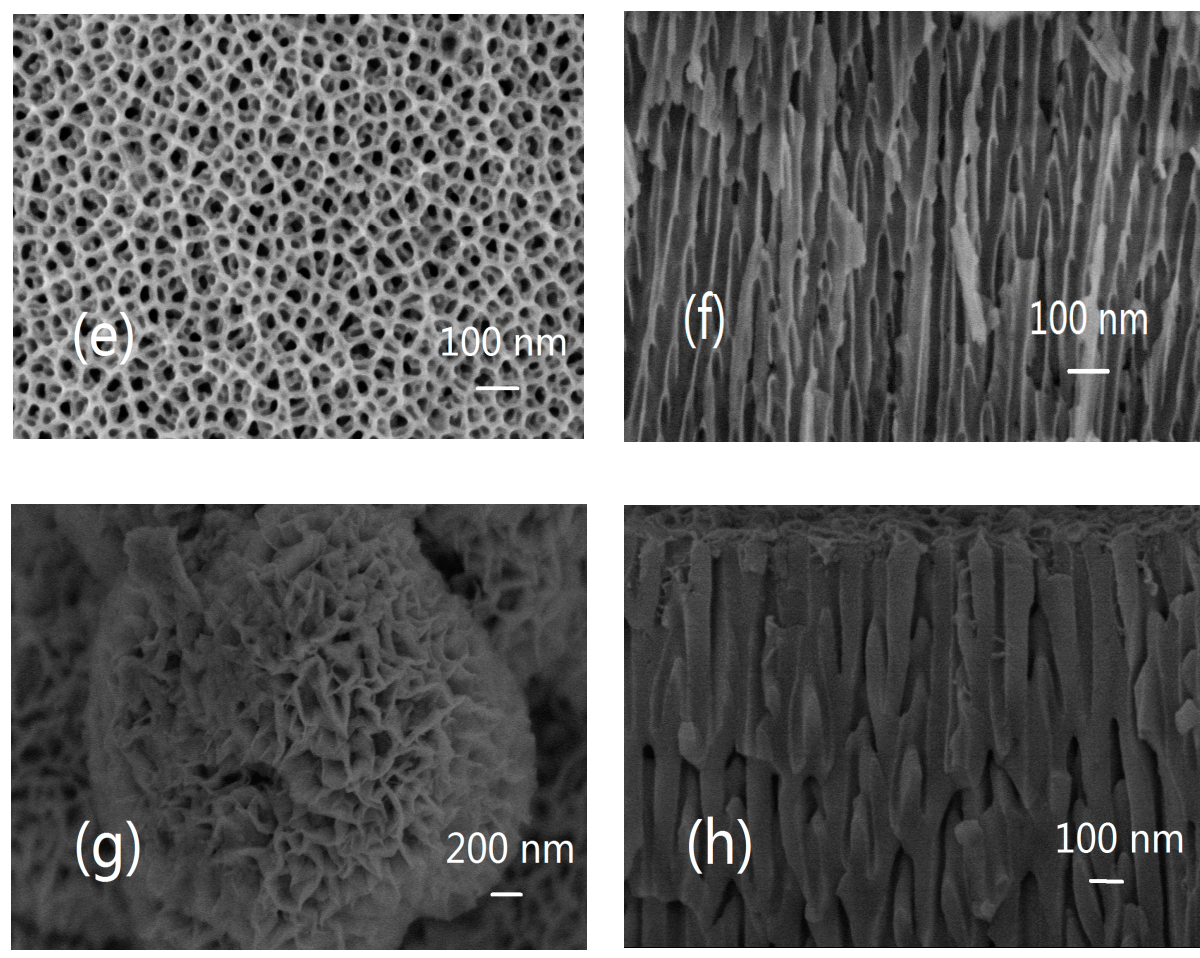

Figure 1. SEM images of the top view and the side view of the traditional alumina film $(\mathbf{a}, \mathbf{b})$ and $\mathrm{Ni}$ deposited on traditional straight pass alumina film (c,d); the ceramic structure alumina film $(\mathbf{e}, \mathbf{f})$ and $\mathrm{Ni}$ deposited on the ceramic structure alumina film $(\mathbf{g}, \mathbf{h})$ by the electrodeposition method.

The SEM images reveal the formation mechanism of the $\mathrm{Ni} / \mathrm{Al}_{2} \mathrm{O}_{3} / \mathrm{Ni}$ composite film (Figure 2a). Ni particles were deposited along alumina nanotubes, which then grew out of the alumina film surface. $\mathrm{Ni}$ formed a branched hollow tubular deposit along the tube wall of the ceramic structure $\mathrm{Al}_{2} \mathrm{O}_{3}$ film instead of being closely packed. Certain angles in the ceramic structure $\mathrm{Al}_{2} \mathrm{O}_{3}$ film provide horizontal force, and due to the space limitation, the Ni petals do not grow indefinitely but form porous spherical flowers and accumulate together into clusters. The $\mathrm{Ni} / \mathrm{Al}_{2} \mathrm{O}_{3} / \mathrm{Ni}$ composite film still has a $3 \mathrm{D}$ connected network structure in the inner cavity. The pore's size can be designed according to specified criteria so that they can be filled with microwave absorbing to conveniently provide expected material properties [12]. The 3D connected network inside $\mathrm{Al}_{2} \mathrm{O}_{3}$ provides effective isolation and prevents nickel agglomeration.

The flower-like $\mathrm{Ni} / \mathrm{Al}_{2} \mathrm{O}_{3} / \mathrm{Ni}$ film was prepared on the surface of the ceramic structure alumina, whereas the grain-like structural membrane was prepared on the surface of traditional straight pass alumina via electrodeposition. The Ni particles grew along the tube walls inside the alumina and formed a flower-like structure (Figure 2b). The reason for the synthesized grain-like Ni surface may be that the deposited Ni grew along the tube walls inside traditional straight pass alumina and formed a vertical pipe structure, which resulted in $\mathrm{Ni}$ accumulation on the surface forming grain-like particles (Figure 2c). The tube walls inside the alumina effectively isolated the agglomeration of the Ni layer, which would strongly reduce the magnetic field consumption caused by the eddy current effect. 


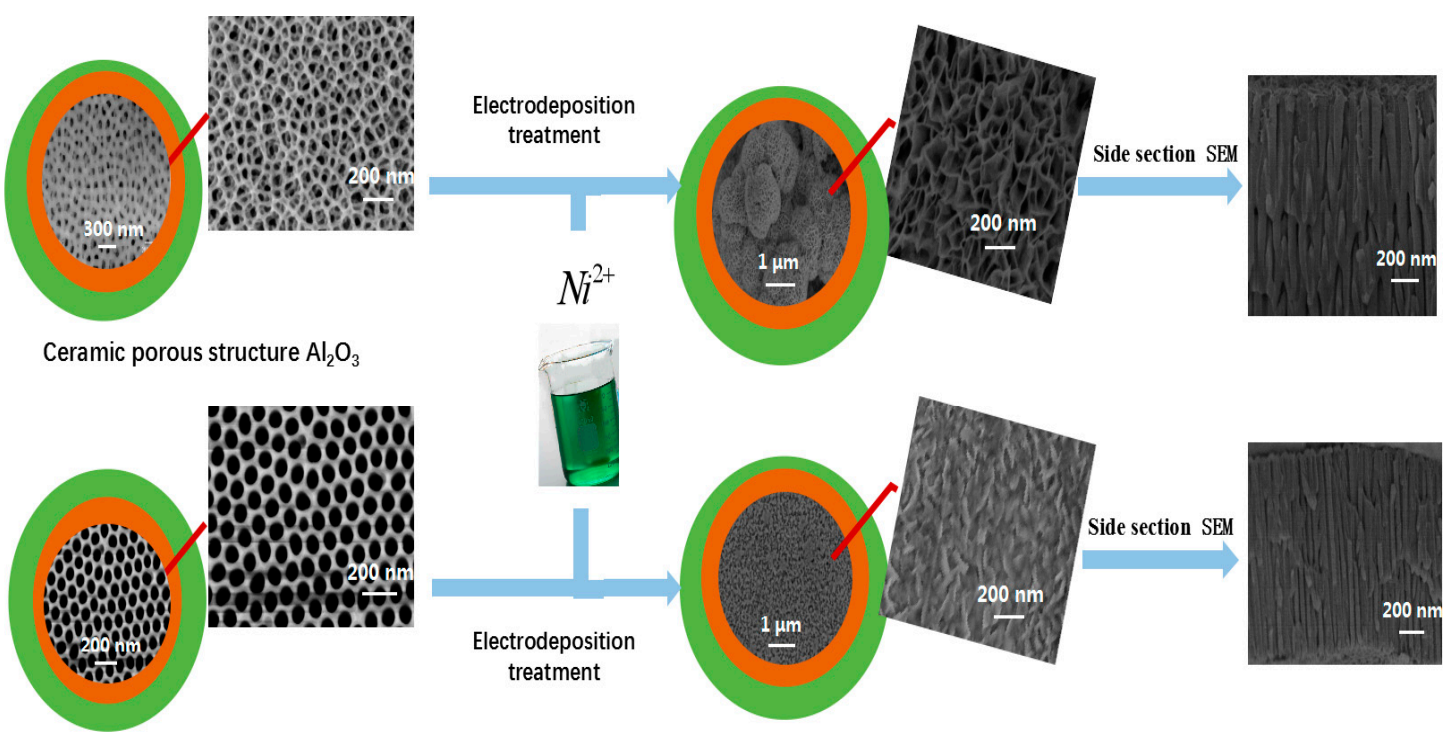

Traditional straight hole structure $\mathrm{Al}_{2} \mathrm{O}_{3}$

(a)

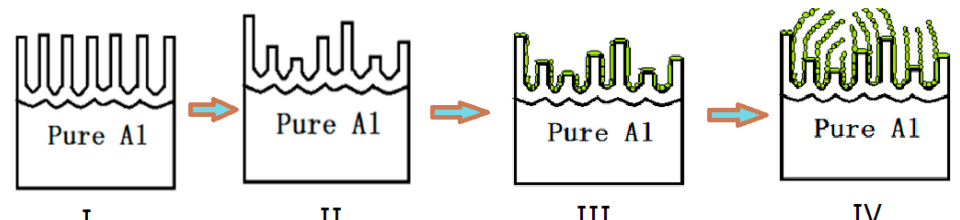

(b)

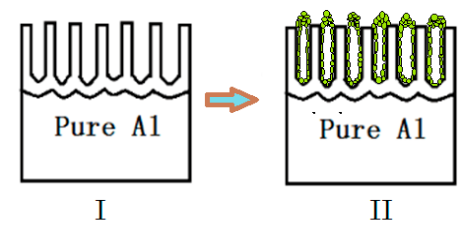

(c)

Figure 2. (a) Diagram of preparation process of $\mathrm{Ni} / \mathrm{Al}_{2} \mathrm{O}_{3} / \mathrm{Ni}$ composite films; (b,c) growth mechanism of two kinds of $\mathrm{Ni} / \mathrm{Al}_{2} \mathrm{O}_{3} / \mathrm{Ni}$ composite films.

According to EDS (Figure 3), the membrane components were $\mathrm{Ni}, \mathrm{Al}$, and $\mathrm{O}$; no other electrolyte material was found. Tables 1 and 2 correspond to the component content data of Figure $3 a, b$ respectively. From Tables 1 and 2, the Ni content was $5 \mathrm{wt} \%$, demonstrating a thinner coating layer than the alumina sheet, although the $\mathrm{Ni}$ content was not high compared with the aluminum oxide film prepared. A series of experimental results below showed that this Ni content is sufficient to produce ferromagnetism and microwave absorption, and the hollow structure and crystal form of Ni particles play the most important roles in creating microwave absorption characteristics. The Ni layer is much thinner than the alumina sheet, a large amount of Ni particles piled up like many small protrusions on the alumina surface. However, the $\mathrm{Ni}$ content in the flower-like $\mathrm{Ni} / \mathrm{Al}_{2} \mathrm{O}_{3} / \mathrm{Ni}$ film (Figure $3 \mathrm{a}$ ) was slightly higher than in the grain-like $\mathrm{Ni} / \mathrm{Al}_{2} \mathrm{O}_{3} / \mathrm{Ni}$ film (Figure 3a) because the flower-like Ni produced by electrochemical deposition extended to the external 3D space to increase the space for Ni growth and increase the content. According to the uniform high definition imaging for the entire observation area of the Ni map, we deduced that flower-like $\mathrm{Ni} / \mathrm{Al}_{2} \mathrm{O} / \mathrm{Ni}_{3}$ has homogeneous growth on the micrometer scale (Figure 3c). 

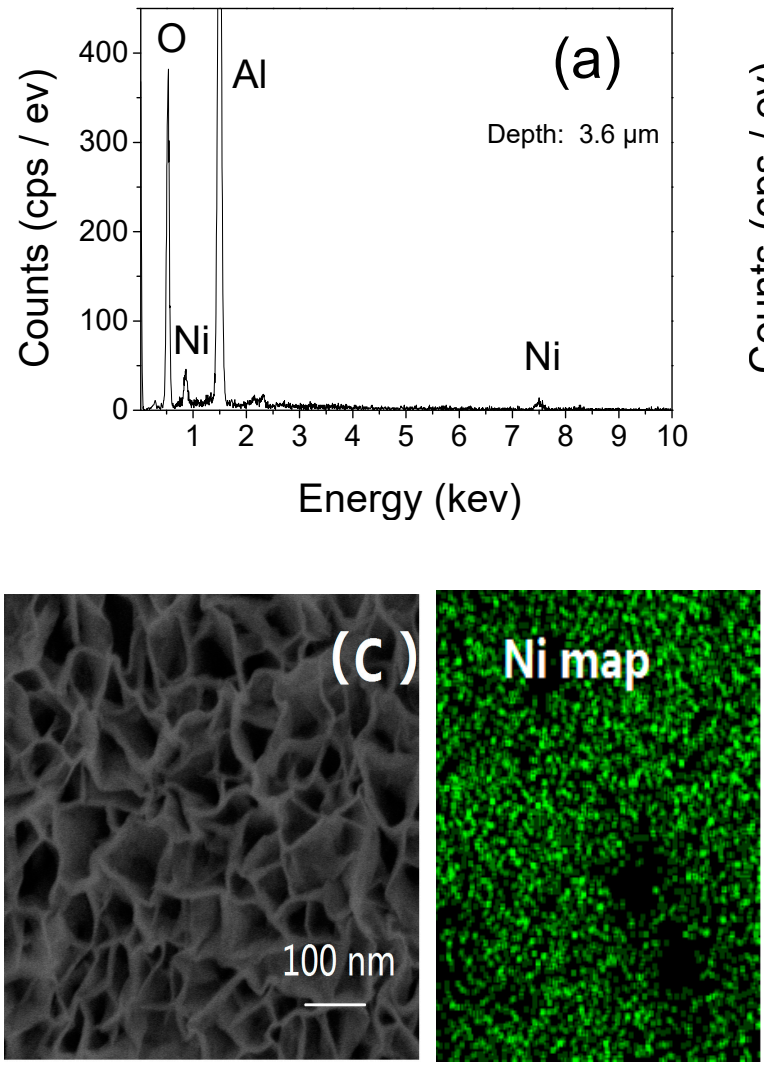

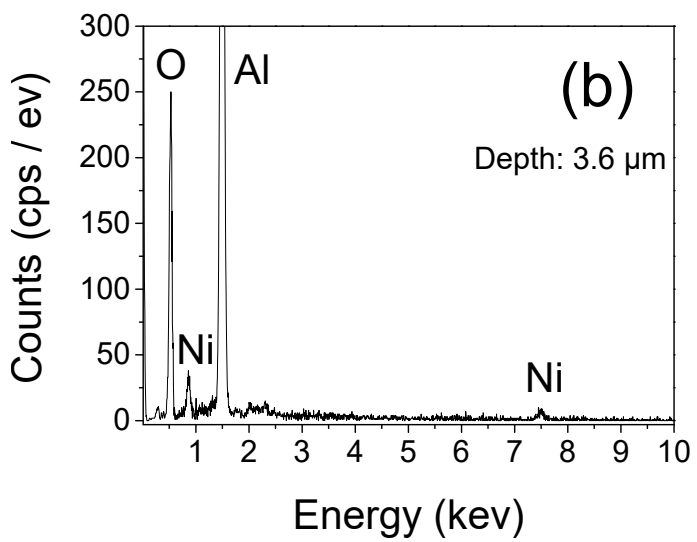

Figure 3. EDS pattern of the as-prepared (a) flower-like and (b) grain-like $\mathrm{Ni} / \mathrm{Al}_{2} \mathrm{O}_{3} / \mathrm{Ni}$ film and (c) enlarged SEM image of the flower-like $\mathrm{Ni} / \mathrm{Al}_{2} \mathrm{O}_{3} / \mathrm{Ni}$ film and the corresponding mapping of $\mathrm{Ni}, \mathrm{Al}$, and $\mathrm{O}$.
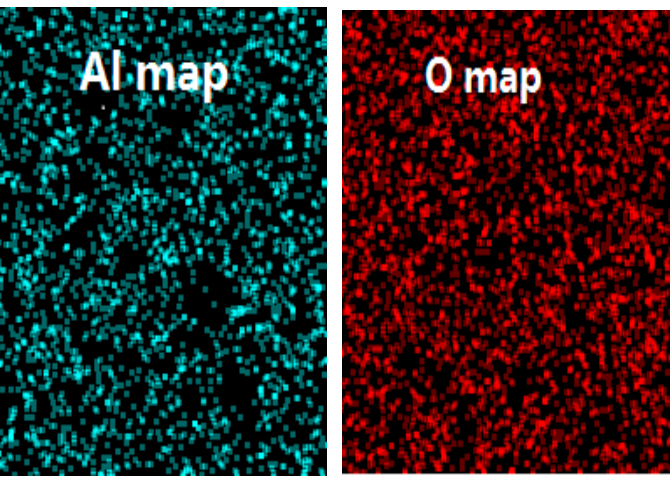

Table 1. EDS pattern of as-prepared flower-like $\mathrm{Ni} / \mathrm{Al}_{2} \mathrm{O}_{3} / \mathrm{Ni}$ film.

\begin{tabular}{cccccc}
\hline Element & Atomic Number & $\begin{array}{c}\text { Unnormalization } \\
(\mathbf{w t} \%)\end{array}$ & Normalization (wt \%) & $\begin{array}{c}\text { Atomic Percentage } \\
\text { (at \%) }\end{array}$ & Error (wt \%) \\
\hline $\mathbf{A l}$ & 13 & 35.81 & 52.24 & 66.92 & 5.7 \\
$\mathbf{O}$ & 8 & 27.41 & 39.98 & 30.37 & 5.4 \\
$\mathbf{N i}$ & 28 & 5.33 & 7.7 & 2.71 & 0.4 \\
\hline
\end{tabular}

Table 2. EDS pattern of as-prepared grain-like $\mathrm{Ni} / \mathrm{Al}_{2} \mathrm{O}_{3} / \mathrm{Ni}$ film.

\begin{tabular}{cccccc}
\hline Element & Atomic Number & $\begin{array}{c}\text { Unnormalization } \\
\text { (wt \%) }\end{array}$ & Normalization (wt \%) & $\begin{array}{c}\text { Atomic Percentage } \\
\text { (at \%) }\end{array}$ & Error (wt \%) \\
\hline $\mathbf{A l}$ & 13 & 33.89 & 49.50 & 39.05 & 1.7 \\
$\mathbf{O}$ & 8 & 30.15 & 44.05 & 58.61 & 1.4 \\
$\mathbf{N i}$ & 28 & 4.42 & 6.45 & 2.34 & 0.4 \\
\hline
\end{tabular}

The ceramic-based composite with flower-like Ni deposited on $\mathrm{Al}_{2} \mathrm{O}_{3}$ nanotubes was fabricated using electrochemistry, and the small-angle XRD diffraction spectrum showed crystals with a face-centered cubic structure and three characteristic peaks at $44.49^{\circ}, 51.85^{\circ}$, and $76.56^{\circ}$ in the lattice plane index (Figure 4a). The XRD diffraction peaks for the grain-like $\mathrm{Ni} / \mathrm{Al}_{2} \mathrm{O}_{3} / \mathrm{Ni}$ film were located at $45.05^{\circ}, 52.53^{\circ}$, and $76.86^{\circ}$, corresponding to the Ni crystal face (111), (200) and (220), respectively (Figure $4 \mathrm{~b}$ ), which matches the nickel pattern according to the international standard card JCPDS: $65-2865$. The $40.22^{\circ}, 46.38^{\circ}, 67.49^{\circ}$ diffraction peak was related to the $\gamma-\mathrm{Al}_{2} \mathrm{O}_{3}$ basement, because the Ni deposition layer on the surface of the sample is relatively thin, the space size of granular $\mathrm{Ni}$ particles is much smaller than that of flower-like Ni (see Figure 1), and the depth of diffraction of 
XRD by small-angle diffraction is easier to hit the $\mathrm{Al}_{2} \mathrm{O}_{3}$ substrate. The average size of the grains can be calculated using the Scherrer formula [13]:

$$
\mathrm{D}=\frac{0.89 \lambda}{\beta \cos \theta}
$$

where $D$ is the average grain size, $\theta$ is the second diffraction angle, $\lambda$ is the wavelength of the $X$-ray $(\lambda=1.5406 \AA)$, and $\beta$ is the integral half-width. Because the characteristic peaks of the $\mathrm{Al}$ and $\mathrm{Al}_{2} \mathrm{O}_{3}$ matrix are the extraneous peaks of the electrodes, they can be ignored when calculating the average size of the grains using the Scherrer formula. The calculated average grain size of Ni was about $9.7 \pm 0.1 \mathrm{~nm}$. The Curie temperature of magnetic metal absorbing material is high, and magnetic metal is prone to the eddy current phenomenon, which reduces its saturation magnetization and weakens the absorption of the microwave. The diffraction peaks of Ni widened, apparently due to its nanoscale effect, and the peaks were sharp, indicating good crystallinity. No other impurity peaks, such as $\mathrm{NiO}$ or $\mathrm{Ni}(\mathrm{OH})_{2}$, were detected. The shape of the Ni crystals is mainly affected by the relative Ni growth rate in different $\mathrm{Al}_{2} \mathrm{O}_{3}$ channel directions; rugged channels grow into flower-like $\mathrm{Ni}$, whereas straight channels grow into grain-like $\mathrm{Ni}$ [14].
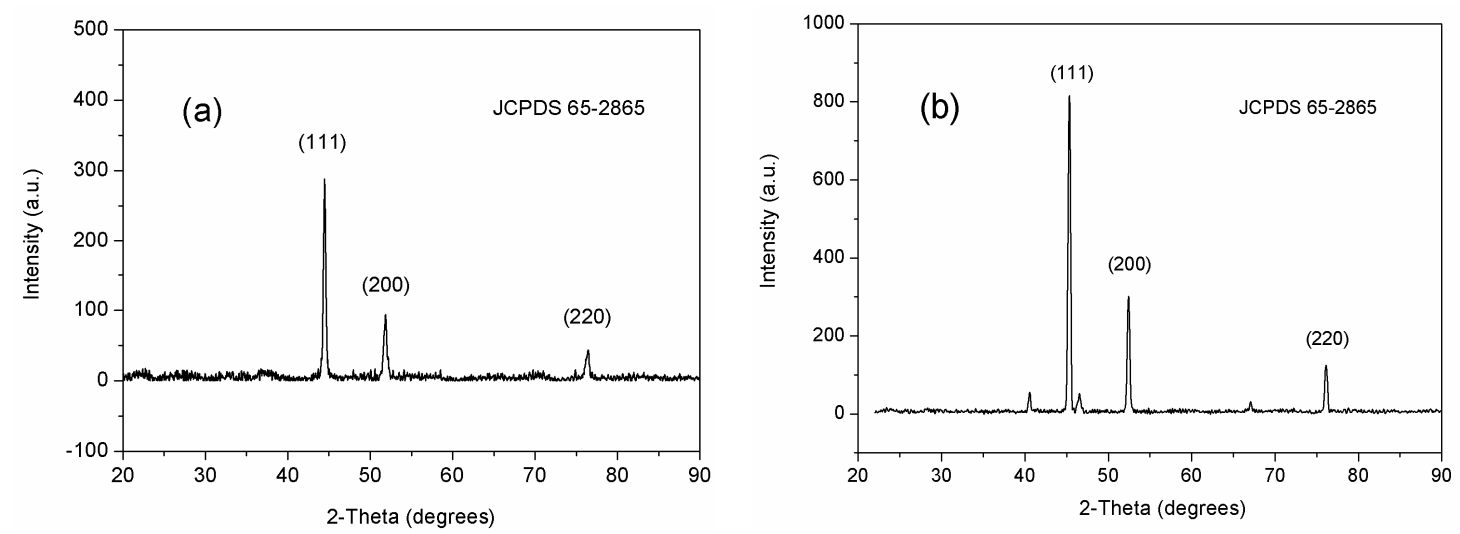

Figure 4. Small-angle XRD diffraction spectrum of the (a) flower-like $\mathrm{Ni} / \mathrm{Al}_{2} \mathrm{O}_{3} / \mathrm{Ni}$ film and (b) grain-like $\mathrm{Ni} / \mathrm{Al}_{2} \mathrm{O}_{3} / \mathrm{Ni}$ film.

The hysteresis loop curves of flower- and grain-like $\mathrm{Ni} / \mathrm{Al}_{2} \mathrm{O}_{3} / \mathrm{Ni}$ were measured by VSM at room temperature $\left(25^{\circ} \mathrm{C}\right)$, as shown in Figure 5. The two samples revealed the ferromagnetic properties of the coercivity $(\mathrm{Hc})$, the saturation magnetization $(\mathrm{Ms})$, and the residual magnetization $(\mathrm{Mr})$ values of the flower-like $\mathrm{Ni} / \mathrm{Al}_{2} \mathrm{O}_{3} / \mathrm{Ni}$ were $110 \mathrm{Oe}, 1.09 \mathrm{emu} / \mathrm{g}\left(1 \mathrm{emu} / \mathrm{g}=1 \mathrm{Am}^{2} / \mathrm{kg}\right)$, and $0.376 \mathrm{emu} / \mathrm{g}$, respectively; those of the grain-like $\mathrm{Ni} / \mathrm{Al}_{2} \mathrm{O}_{3} / \mathrm{Ni}$ were $105 \mathrm{Oe}, 0.849 \mathrm{em} \mu / \mathrm{g}$, and $0.25 \mathrm{em} \mu / \mathrm{g}$, respectively. However, the intrinsic magnetic properties with high saturation magnetization (Ms) and low coercivity (Hc), which bring a good permeability and magnetic loss and further contribute to the microwave absorption. The two samples' saturation magnetization were very close [15]. However, compared with the Hc value of pure $\mathrm{Ni}(0.7 \mathrm{Oe})$ [16], the coercivity value of the grain-like $\mathrm{Ni} / \mathrm{Al}_{2} \mathrm{O}_{3} / \mathrm{Ni}$ is a little lower than that of flower-like $\mathrm{Ni} / \mathrm{Al}_{2} \mathrm{O}_{3} / \mathrm{Ni}$. This phenomenon may be due to the increased content of Ni nanoparticles; the reduction in particle size synergistically strengthens the magnetization reversal mechanism [17,18]. Pang et al. [19] reported that the electrons' spin state and size effect of Ni nanoparticles are the main factors determining their magnetic properties. 


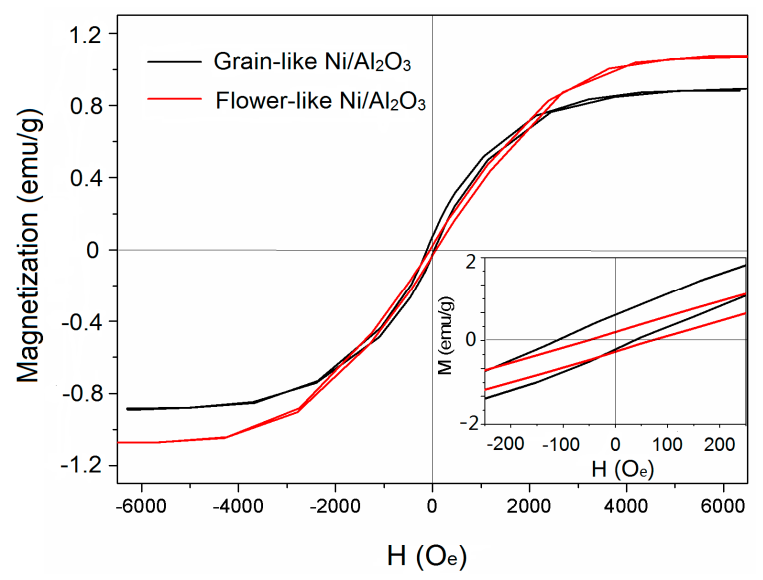

Figure 5. Hysteresis loop curves of flower-like and grain-like $\mathrm{Ni} / \mathrm{Al}_{2} \mathrm{O}_{3} / \mathrm{Ni}$ films.

The loops of two samples in the direction of the X-axis both showed a narrow rectangular shape, almost coinciding and crossing diagonally in the direction of the $X$-axis. Comparing the hysteresis loops on the $\mathrm{Y}$ with the $\mathrm{X}$-axis, the samples had a static in-plane uniaxial anisotropy field $\left(\mathrm{H}_{\mathrm{k} \text {-stat }}\right)$ [20]. The exchange coupling effects of multilayer samples include additional interlayer coupling effects when the layer thickness is suitable. According to the cave model proposed by Grunberg et al., when two ferromagnetic layers are separated by a nanometer insulation layer and the thickness of the insulation layer is relatively thin (generally does not exceed $2 \mathrm{~nm}$ ), the ferromagnetic layer can be completely isolated. The ferromagnetic $\mathrm{Ni}$ layers on both sides of the whole walls of $\mathrm{Al}_{2} \mathrm{O}_{3}$ are inclined to be arranged in parallel, so interlayer exchange coupling can be easily obtained in thin films under an externally induced magnetic field [21,22]. Based on the XRD diffraction spectrum and hysteresis loop curves, the coupling action among $\mathrm{Ni} / \mathrm{Al}_{2} \mathrm{O}_{3} / \mathrm{Ni}$ particles can overcome the effect of thermal disturbance and form a continuous magnetic structure with the size of a single magnetic particle.

Of the total energy of microwave absorbed, $-10 \mathrm{~dB}$ is equivalent to $90 \%$ and $-20 \mathrm{~dB}$ is equivalent to $99 \%$ [23]. The $\mathrm{RL}_{\max }$ of pure $\mathrm{Ni} / \mathrm{Al}_{2} \mathrm{O}_{3}$ powder could only reach $-3.4 \mathrm{~dB}$, and could not achieve the effective bandwidth (Figure 6a). When the thickness of flower-like $\mathrm{Ni} / \mathrm{Al}_{2} \mathrm{O}_{3} / \mathrm{Ni}$ sample is $3.5 \mathrm{~mm}$ and the effective absorption bandwidth ( $\mathrm{RL} \leq-10 \mathrm{~dB})$ is $7.1 \mathrm{GHz}$, the microwave maximum reflection loss $\left(\mathrm{RL}_{\max }\right)$ is $-45.3 \mathrm{~dB}$ at $11.4 \mathrm{GHz}$ (Figure $6 \mathrm{~b}$ ). The $\mathrm{RL}_{\max }$ of grain-like $\mathrm{Ni} / \mathrm{Al}_{2} \mathrm{O} / \mathrm{Ni}_{3}$ reaches $-28.2 \mathrm{~dB}$ corresponding to a thickness of $4.5 \mathrm{~mm}$ at $12.92 \mathrm{GHz}$, and effective absorption bandwidth is about $5.5 \mathrm{GHz}$ (Figure 6c). The $\mathrm{RL}_{\max }$ and effective bandwidth of the flower-like $\mathrm{Ni} / \mathrm{Al}_{2} \mathrm{O}_{3} / \mathrm{Ni}$ sample is $17.1 \mathrm{~dB}$ and $1.6 \mathrm{GHz}$ higher than that of the grain-like $\mathrm{Ni} / \mathrm{Al}_{2} \mathrm{O}_{3} / \mathrm{Ni}$ sample, correspondingly. The flower-like $\mathrm{Ni} / \mathrm{Al}_{2} \mathrm{O}_{3} / \mathrm{Ni}$ has more absorption capacity than the grain-like $\mathrm{Ni} / \mathrm{Al}_{2} \mathrm{O}_{3} / \mathrm{Ni}$ because of ceramics porous structure inside flower-like $\mathrm{Ni} / \mathrm{Al}_{2} \mathrm{O}_{3} / \mathrm{Ni}$ help provide isolation of $\mathrm{Ni}$ particles agglomeration, especially at the absorption bandwidth of the maximum absorbed microwave intensity. To some extent, the porous ceramic structure improves the microwave absorption performance of $\mathrm{Ni} / \mathrm{Al}_{2} \mathrm{O}_{3} / \mathrm{Ni}$, enhancing the internal refraction absorption and the dielectric polarization of $\mathrm{Ni}$, which promotes the attenuation of microwaves. The main function of the porous structure of $\mathrm{Al}_{2} \mathrm{O}_{3}$ prepared in this study is the promotion of the growth of porous nickel, providing a support function similar to a skeleton, which is conducive to the formation of magnetic crystals by Ni particles. The flower- and grain-like $\mathrm{Ni} / \mathrm{Al}_{2} \mathrm{O}_{3} / \mathrm{Ni}$ samples have better microwave absorption properties than that pure $\mathrm{Ni} / \mathrm{Al}_{2} \mathrm{O}_{3}$; hence, we microwave active materials with the multilevel 3D tubular structure could be developed, which would reflect and absorb microwaves many times inside the ceramic $\mathrm{Ni} / \mathrm{Al}_{2} \mathrm{O}_{3} / \mathrm{Ni}$ film [24]. The ceramic flower-like $\mathrm{Ni} / \mathrm{Al}_{2} \mathrm{O}_{3} / \mathrm{Ni}$ has a high aspect ratio, lower density, and lower content of metallic Ni due to the tubular structure compared with pure $\mathrm{Ni} / \mathrm{Al}_{2} \mathrm{O}_{3}$ powder. Other metals or alloys, e.g., $\mathrm{Co}$ and $\mathrm{Fe}$, could also be deposited into porous ceramic $\mathrm{Al}_{2} \mathrm{O}_{3}$ nanotubes to tune the microwave absorption properties of the porous composites. 

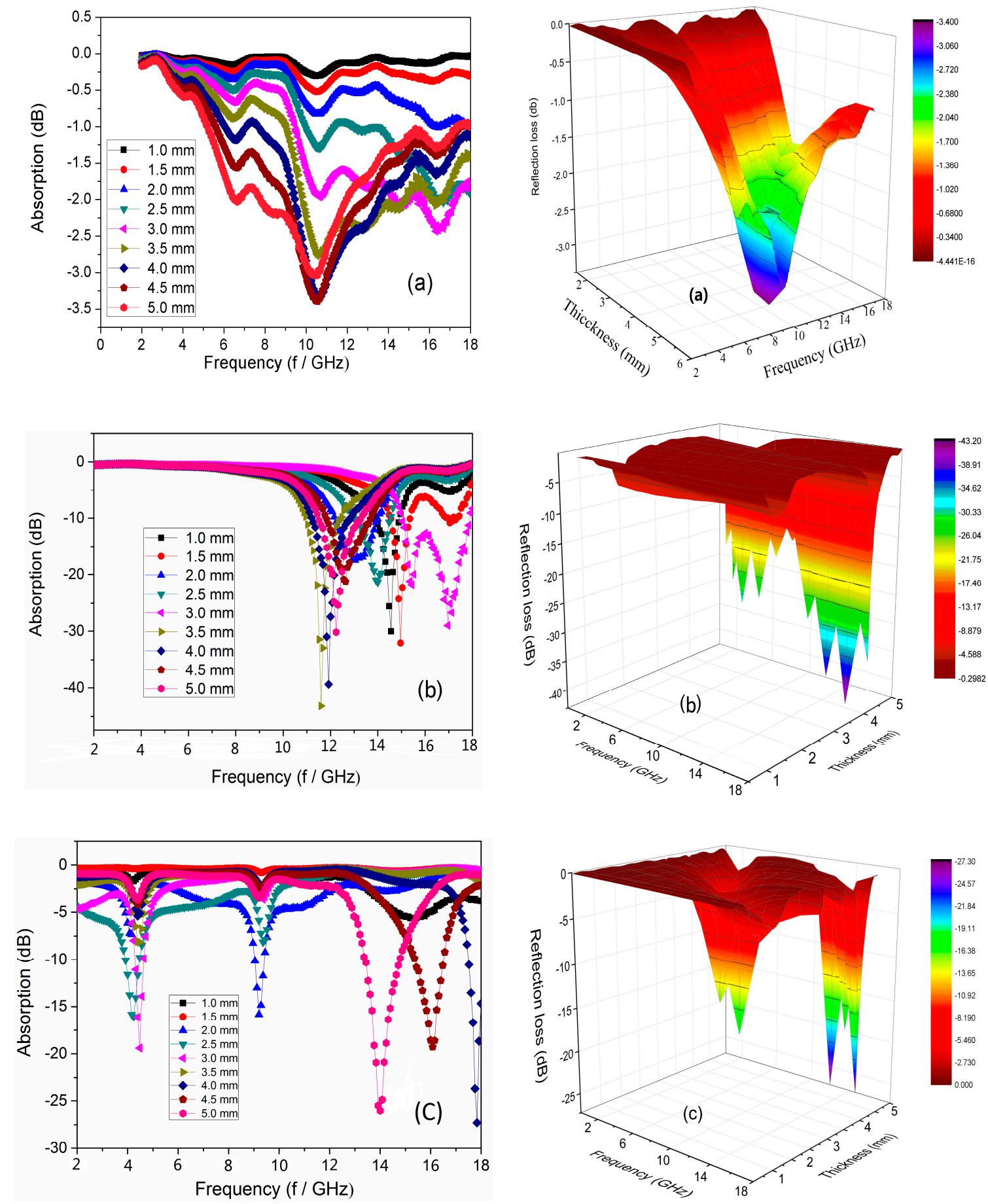

Figure 6. The microwave absorbing (RL) curves with different thicknesses in the same sample of a frequency range of 2 to $18 \mathrm{GHz}$ (on the left) and the corresponding 3D depth maps (on the right). Samples of (a) pure $\mathrm{Ni} / \mathrm{Al}_{2} \mathrm{O}_{3}$ composites, (b) flower-like $\mathrm{Ni} / \mathrm{Al}_{2} \mathrm{O}_{3} / \mathrm{Ni}$, and (c) grain-like $\mathrm{Ni} / \mathrm{Al}_{2} \mathrm{O}_{3} / \mathrm{Ni}$ prepared on the surface of traditional straight pass alumina. All samples have the same thickness of the test.

Figure 7 demonstrates the relationship between the real part and the imaginary part of complex permittivity, real part and imaginary part of complex permeability with the frequency of the flower-like, grain-like, and pure $\mathrm{Ni} / \mathrm{Al}_{2} \mathrm{O}_{3} / \mathrm{Ni}$ samples. The flower-like $\mathrm{Ni} / \mathrm{Al}_{2} \mathrm{O}_{3} / \mathrm{Ni}$ permittivity (real part) $\varepsilon^{\prime}$ value changes within a narrow range around 19 in the frequency range of 2 to $11 \mathrm{GHz}$, which is much larger than that of the grain-like sample (Figure 7a). Similarly, the $\varepsilon^{\prime}$ values of the grain-like 
$\mathrm{Ni} / \mathrm{Al}_{2} \mathrm{O}_{3} / \mathrm{Ni}$ and pure $\mathrm{Ni} / \mathrm{Al}_{2} \mathrm{O}_{3}$ samples were about nine and six, respectively, and the values of the changes in the imaginary part $\varepsilon^{\prime \prime}$ were in the range of 0.2 to 1.2 (Figure $7 \mathrm{~b}$ ). The ceramics flower-like $\mathrm{Ni} / \mathrm{Al}_{2} \mathrm{O}_{3} / \mathrm{Ni}$ sample was semiconductor-like and a small number of electrons in the core could participate in conduction through the Ni layer. Therefore, we initially established the connected network $\mathrm{Ni} / \mathrm{Al}_{2} \mathrm{O}_{3} / \mathrm{Ni}$ composite material system. Due to the electrical conductivity and alternating microwave-field-induced eddy current in the flower-like $\mathrm{Ni}$, the eddy current can be isolated by an $\mathrm{Al}_{2} \mathrm{O}_{3}$ insulating medium, and the temperature generated by eddy current can be effectively reduced [25]. The real part $\varepsilon^{\prime}$ of the permittivity increased gradually with the frequency of the alternating microwave field; as the relationship between the complex permittivity's imaginary part $\varepsilon^{\prime \prime}$ and the conductivity $\varepsilon^{\prime \prime} \approx \sigma / 2 \pi f \varepsilon_{0}$ is constant (where $\sigma, \mathrm{f}$, and $\varepsilon_{0}$ are the resistivity, the frequency and the dielectric constant of free space, respectively.), the imaginary part $\varepsilon^{\prime \prime}$ of the $\mathrm{Ni} / \mathrm{Al}_{2} \mathrm{O}_{3} / \mathrm{Ni}$ nanoparticles increases with increasing frequency [26]. Generally speaking, the magnetic loss mainly comes from magnetization vector rotation, hysteresis loss, magnetic domain wall resonance, natural resonance, and eddy current loss. Among them, the magnetization vector rotation mainly occurs under the action of a strong magnetic field, the lag loss of soft magnetic materials is very limited, and the domain wall resonance mainly occurs in the range of $1-100 \mathrm{MHz}$, so the electromagnetic wave loss of sample mainly comes from natural resonance and eddy current loss. However, the magnitude of eddy current loss is related to the thickness $(\mathrm{d})$ and electrical conductivity $(\sigma)$ of the absorber, which can be expressed by the following formula [27]:

$$
\mu_{r}^{\prime \prime}=3 \pi \mu_{0}\left(\mu^{\prime}\right)^{2} \sigma \mathrm{d}^{2} \mathrm{f}
$$
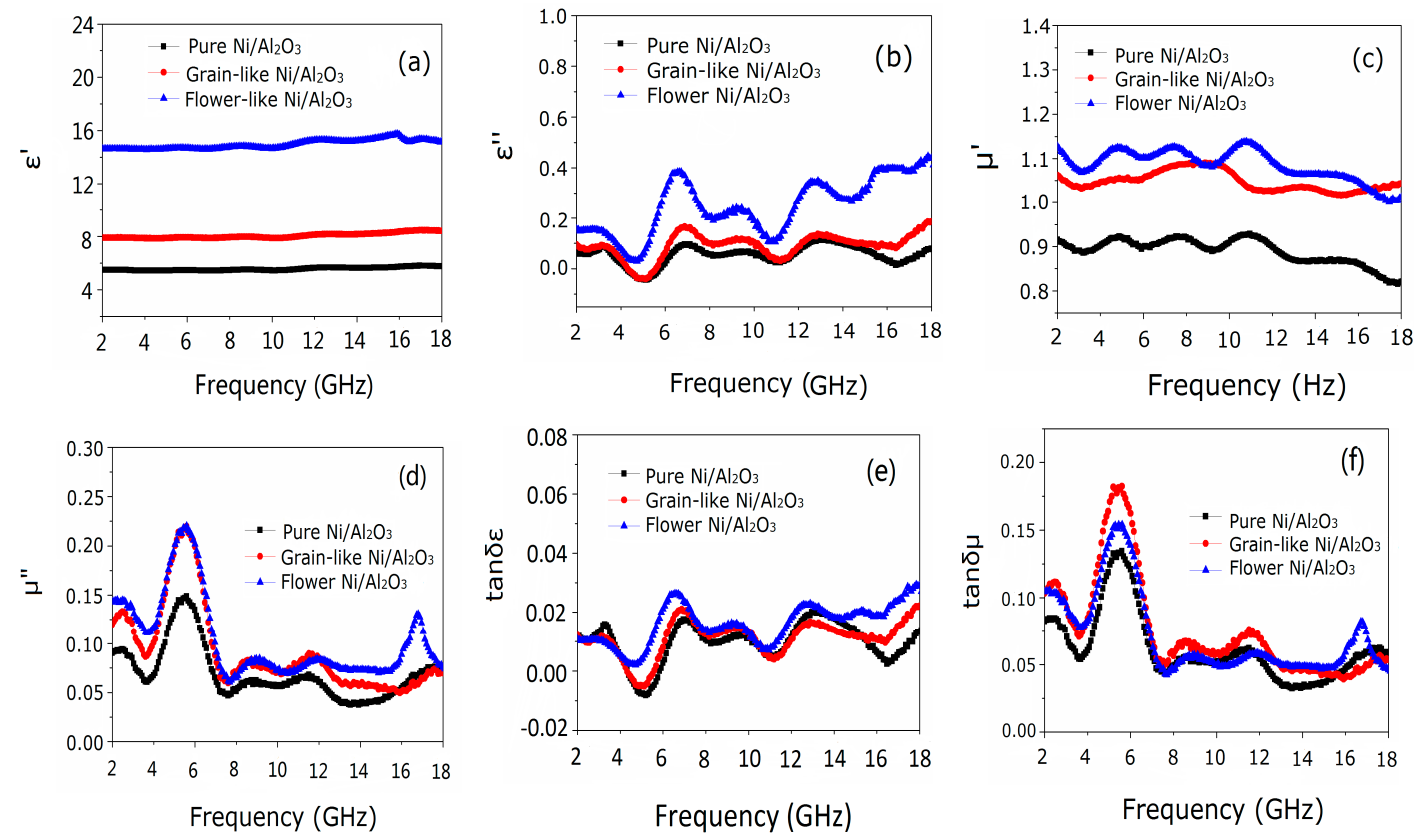

Figure 7. Electromagnetic parameters of three $\mathrm{Ni} / \mathrm{Al}_{2} \mathrm{O}_{3} / \mathrm{Ni}$ samples: real (a), imaginary (b) part of the complex permittivity; real (c), imaginary (d) part of the complex permeability and tangent dielectric loss (e) and tangent magnetic loss (f) in the frequency range of 2-18 GHz.

In Equation (2), $d$ is the thickness of the absorber, $f$ is the frequency of the microwave, $\mu_{0}$ is permeability in a vacuum. If the magnetic loss of samples all comes from eddy current loss, then the value is constant in the measured frequency range [28]. As shown in Figure $7, \mu^{\prime \prime}\left(\mu^{\prime}\right)^{-2} \mathrm{f}^{-1}$ is not a constant as the frequency increases, therefore, the microwave loss of the sample mainly comes from the natural resonance and occurs in ranges of $4-8 \mathrm{GHz}$ and $16-18 \mathrm{GHz}$ (Figure 7c,d).

From the composite complex imaginary part of the permeability constant values of $\mathrm{Ni} / \mathrm{Al}_{2} \mathrm{O}_{3} / \mathrm{Ni}$ samples, we observed several peaks in the frequency range of $4-8 \mathrm{GHz}$. The main reason for these 
peaks is the quantum size effect of Ni nanoparticles that results in the separation of electron energy levels [29]. The composite has low magnetic conductivity, magnetic loss, and dielectric loss values under an applied magnetic field within $2-18 \mathrm{GHz}$. The change in the tangent dielectric loss $\tan \delta \varepsilon(\tan \delta \varepsilon$ $\left.=\varepsilon^{\prime \prime} / \varepsilon^{\prime}\right)$ and tangent magnetic loss $\tan \delta \mu\left(\tan \delta \mu=\mu^{\prime \prime} / \mu^{\prime}\right)$ of the grain-like $(0.33$ and 0.14$) \mathrm{Ni} / \mathrm{Al}_{2} \mathrm{O}_{3} / \mathrm{Ni}$ are greater than that of the flower-like sample ( 0.29 and 0.11 , Figure $7 \mathrm{e}, \mathrm{f})$.

$\alpha$ is the electromagnetic attenuation constant and is the main parameter of the microwave attenuation effect of the reaction material, and can be calculated by the following calculation formula:

$$
\alpha=C \sqrt{\mu^{\prime} \varepsilon^{\prime}} \cdot \sqrt{\frac{1}{2}\left|\tan \delta_{\varepsilon} \tan \delta_{\mu}-1+\sqrt{1+\tan ^{2} \delta_{\varepsilon}+\tan ^{2} \delta_{\mu}+\tan ^{2} \delta_{\varepsilon} \tan ^{2} \delta_{\mu}}\right|}
$$

where $C$ is the attenuation coefficient of the material. The dielectric loss angle tangent $\tan \delta \varepsilon$ (around 0.01 ) of the three $\mathrm{Ni} / \mathrm{Al}_{2} \mathrm{O}_{3} / \mathrm{Ni}$ samples was much smaller than $\tan \delta \mu$ (around 0.1), the electromagnetic attenuation constant is dominated by magnetic attenuation, so the microwave absorbing mechanism of $\mathrm{Ni} / \mathrm{Al}_{2} \mathrm{O}_{3} / \mathrm{Ni}$ mainly depends on magnetic loss.

Flower-like and granular $\mathrm{Ni} / \mathrm{Al}_{2} \mathrm{O}_{3} / \mathrm{Ni}$ samples both have nanopores inside (Figure $8 \mathrm{a}$ ), but the composite membrane constructed on the surface of $\mathrm{Al}_{2} \mathrm{O}_{3}$ film with a ceramic structure has a larger pore diameter and better nitrogen adsorption-desorption capacity than that of the traditional $\mathrm{Al}_{2} \mathrm{O}_{3}$ film (Figure $8 \mathrm{~b}$ ). Capillary condensation extends to $\mathrm{P} / \mathrm{P}_{0}$ indicates that the alumina pores in the composite membrane are completely filled and the structural porosity is high, which is consistent with the results of SEM. According to the effective medium theory, the effective dielectric constant is reduced by dispersion of magnetic particles, and the impedance matching condition can be improved [30]. The large porosity indicates that there are large numbers of porous structures in this membrane, which can promote its microwave absorption capacity. The combination of magnetic characteristics of $\mathrm{Ni}$ and the porous structure of the ceramic alumina structure enhances the electromagnetic wave and magnetic absorption properties of the composite porous $\mathrm{Ni} / \mathrm{Al}_{2} \mathrm{O}_{3} / \mathrm{Ni}$. As a result, it is more beneficial to add other materials that are beneficial to improving microwave absorption or electromagnetic performance through its porous structure, such as graphite, carbon-containing manganese oxide powder, etc. [31]. The dense material is designed as a porous material, which is equivalent to a large number of air cavities. In addition, the density of porous materials can be markedly reduced to meet the requirements of lightweight stealthy materials.

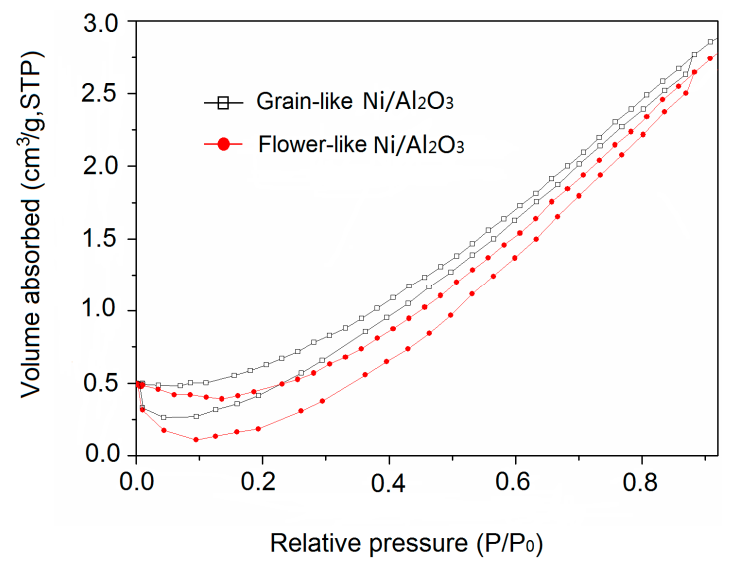

(a)

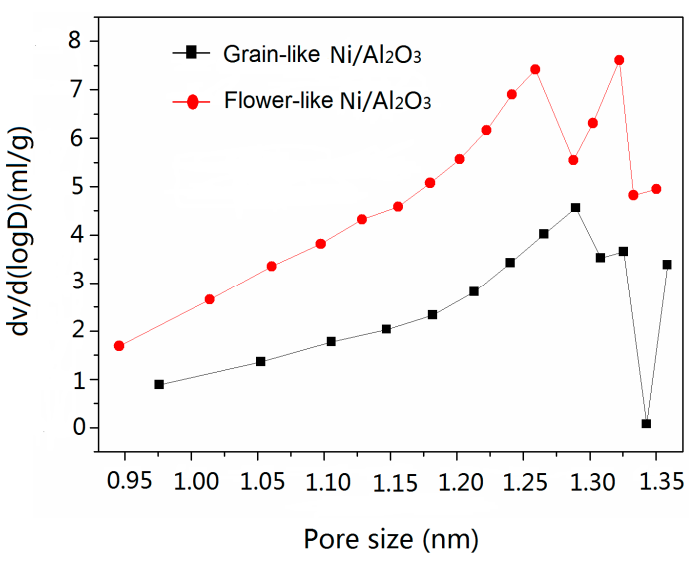

(b)

Figure 8. (a) Nitrogen adsorption-desorption isotherms and (b) pore size distributions of grain-like and flower-like $\mathrm{Ni} / \mathrm{Al}_{2} \mathrm{O}_{3} / \mathrm{Ni}$ film.

Generally speaking, the parameters of porous materials have a certain relation to the effective permittivity and the reflectivity RL. If the porosity of the porous material is $\mathrm{f}$, the dielectric constant 
of the skeleton material is $\varepsilon=\varepsilon^{\prime}+j \varepsilon^{\prime \prime}$, the dielectric constant $j$ of the air cavity is 1 , and the linear approximation models based on the effective dielectric constant are [32]:

$$
\varepsilon_{\varepsilon}=p+\varepsilon(1-p)=f+\varepsilon^{\prime}(1-p)+\varepsilon^{\prime \prime}(1-p)
$$

where $\varepsilon_{\varepsilon}$ is the effective permittivity of porous material. The following formulas according to the effective permittivity $\varepsilon_{\mathcal{\varepsilon}}=\varepsilon_{\mathcal{E}^{\prime}}+\mathrm{j} \varepsilon_{\mathcal{E}^{\prime \prime}}$ [33]:

$$
\begin{gathered}
\varepsilon^{\prime}=\varepsilon_{\infty}+\frac{\varepsilon_{\mathrm{S}}-\varepsilon_{\infty}}{1+\omega^{2} \tau^{2}} \\
\varepsilon^{\prime \prime}=\frac{\sigma}{\omega \varepsilon_{0}}+\frac{\varepsilon_{\mathrm{S}}-\varepsilon_{\infty}}{1+\omega^{2} \tau^{2}} \omega \tau
\end{gathered}
$$

where $\varepsilon_{\infty}$ and $\varepsilon_{\mathrm{S}}$ are the relative permittivity and static permittivity at a high-frequency limit, respectively. When the microwave is perpendicular to the surface of material, the reflectivity RL can be expressed as:

$$
\begin{aligned}
& \operatorname{RL}(\mathrm{dB})=20 \log _{10}\left|\frac{Z_{\text {in }}-1}{Z_{\text {in }}+1}\right| \\
& Z_{\text {in }}=\sqrt{\frac{\mu}{\varepsilon}} \tanh \left(\frac{2 \pi \mathrm{fdj} \sqrt{\mu \varepsilon}}{\mathrm{c}}\right)
\end{aligned}
$$

where $Z_{\text {in }}$ and $Z_{0}$ are the input impedance and free-space impedance, $h$ is the propagation constant of the microwave in material, and $\mathrm{c}$ is the light velocity, respectively. The refractive index $\mathrm{n}$ and extinction coefficient $\mathrm{k}$ of the porous material can be calculated by the following formula [34]:

$$
\begin{aligned}
& \mathrm{n}^{2}=\frac{1}{2}\left(\sqrt{\left(\varepsilon_{\varepsilon}^{\prime}\right)^{2}+\left(\varepsilon_{\varepsilon}^{\prime \prime}\right)^{2}}+\varepsilon_{\varepsilon}^{\prime}\right) \\
& \mathrm{k}^{2}=\frac{1}{2}\left(\sqrt{\left(\varepsilon_{\varepsilon}^{\prime}\right)^{2}+\left(\varepsilon_{\varepsilon}^{\prime \prime}\right)^{2}}-\varepsilon_{\varepsilon}^{\prime}\right)
\end{aligned}
$$

When the electromagnetic wave is perpendicular to the surface of material, the reflectivity $\mathrm{R}$ can be expressed as:

$$
\mathrm{R}=1-\frac{4 \mathrm{n}}{(\mathrm{n}+1)^{2}+\mathrm{k}^{2}}
$$

With the increase in porosity, the effective permittivity and reflectivity of porous materials decrease; the greater the porosity, the more obvious the decrease, which widens the low valley of the reflection band, that is to say, the absorbing bandwidth increases significantly.

\section{Discussion}

Overall, the microwave absorption of the flower-like $\mathrm{Ni} / \mathrm{Al}_{2} \mathrm{O}_{3} / \mathrm{Ni}$ film sample was mainly due to the presence of porous $\mathrm{Ni}$, and we think that $\mathrm{Al}_{2} \mathrm{O}_{3}$ acted as an insulating phase to block the interaction of $\mathrm{Ni}$ particles and avoid the eddy current effect (Figure 9). However, in an ideal state, when a microwave is incident from the air or transition layer onto the interface of $\mathrm{Ni} / \mathrm{Al}_{2} \mathrm{O}_{3} / \mathrm{Ni}$ absorbing layer, one part of the microwave reflects and the other part enters the absorber. When the input impedance of a connected network $\mathrm{Ni} / \mathrm{Al}_{2} \mathrm{O}_{3} / \mathrm{Ni}$ matches the impedance of the air, no reflection of the microwaves occurs on the interface, and all of them enter the absorbing layer medium. In addition, the Ni particles are much smaller than the skin depth and the microwave wavelength. Therefore, ultrafine particles are uniformly magnetized by external alternating microwave fields, and wave energy is dissipated by hysteresis loss, eddy current loss, and other loss mechanisms [35]. Notably, the impurities, the defects, and the interactions between electrons and electrons may all be the reasons for the several tiny impurity absorption peaks in the microwave band [36]. When the microwave is incident, the 3D network 
structure inside the porous $\mathrm{Ni} / \mathrm{Al}_{2} \mathrm{O}_{3} / \mathrm{Ni}$ can be seen as many connected tubular loops, the cut-off grid is like a microwave receiving antenna for the adjacent tubular loops, and polarized current generated under the action of high-frequency magnetic fields propagates from the network surface to inside along the staggered tubular loops rapidly [37]. According to the measurement results of microwave parameters, this propagation is attenuated due to ohmic loss due to the different directions of each tubular loop inside the porous $\mathrm{Ni} / \mathrm{Al}_{2} \mathrm{O}_{3} / \mathrm{Ni}$. The induced fields generated by the polarized current flowing through the tubular loop mostly canceled each other out and resulted in the attenuation of microwave energy. Simultaneously, the incident microwave was scattered and reflected in all directions and resulted in mutual cancellation of microwave energy of opposite directions. Similar to the transmission behavior of microwave in chiral media, most of the incident microwave was lost in the $\mathrm{Ni} / \mathrm{Al}_{2} \mathrm{O}_{3} / \mathrm{Ni} 3 \mathrm{D}$ network.

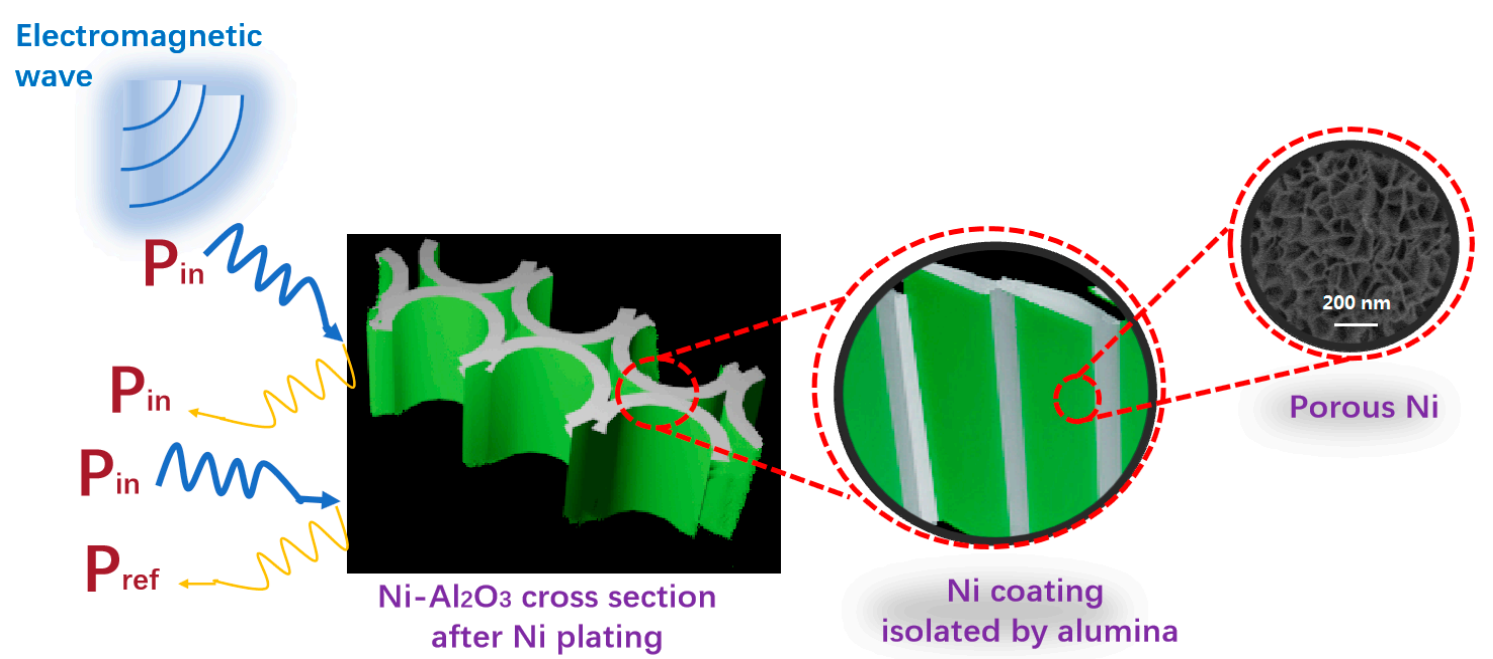

Figure 9. Schematic for the wave absorption mechanisms of $\mathrm{Ni} / \mathrm{Al}_{2} \mathrm{O}_{3} / \mathrm{Ni}$ film cross-section after nickel plating.

\section{Conclusions}

In this study, two interconnected network $\mathrm{Ni} / \mathrm{Al}_{2} \mathrm{O}_{3} / \mathrm{Ni}$ films were fabricated using controllable electrodeposition, their morphology and static magnetic properties were investigated, and the results indicated that the two connected network $\mathrm{Ni} / \mathrm{Al}_{2} \mathrm{O}_{3} / \mathrm{Ni}$ films both have low permittivity, low permeability, low magnetic loss, low dielectric loss, and good microwave absorption properties under an applied magnetic field within a frequency range of $2-18 \mathrm{GHz}$. The 3D connection network loop inside the composite membrane enhances the cancellation of microwaves, the eddy current can be isolated by $\mathrm{Al}_{2} \mathrm{O}_{3}$ insulating medium, and the temperature generated by eddy current effect can be reduced. The XRD of the metallic Ni demonstrated wide peaks due to the nanoscale effect. Such advances were gained by controlled electrochemical deposition allowing the regulation of hole diameters of the $\mathrm{Al}_{2} \mathrm{O}_{3}$ scaffold nanostructure.

Author Contributions: Conceptualization, H.W. and D.S.; methodology, H.W.; data curation, H.W.; writing—original draft preparation, H.W.; formal analysis, D.S.; writing-review and editing, D.S.; supervision, L.C.; project administration, L.C.; funding acquisition, L.C. All authors have read and agreed to the published version of the manuscript.

Funding: This research was funded by Graduate Academic Innovation Project in NUAA, grant number KYLX15_0310.

Conflicts of Interest: The authors declare no conflicts of interest. 


\section{References}

1. Zhu, L.; Zeng, X.; Chen, M.; Yu, R. Controllable permittivity in $3 \mathrm{D} \mathrm{Fe}_{3} \mathrm{O}_{4} / \mathrm{CNTs}$ network for remarkable microwave absorption performances. RSC Adv. 2017, 7, 26801-26808. [CrossRef]

2. Wang, C.; Lv, R.; Kang, F.; Gu, J.; Xuchun, G.; Wu, D. Synthesis and application of iron-filled carbon nanotubes coated with FeCo alloy nanoparticles. J. Magn. Magn. Mater. 2009, 321, 1924-1927. [CrossRef]

3. Wang, Y.; Li, T.; Zhao, L.; Hu, Z.; Gu, Y. Research progress on nanostructured radar absorbing. Energy Power Eng. 2011, 3, 580-584. [CrossRef]

4. Du, G.-X.; Wang, X.-H.; Tu, G.-R.; Zhou, X.-H.; Hao, W.-X. Preparation of microwave absorbing ceramic material by electroless Ni-Co plating. Chin. J. Inorg. Chem. 2006, 22, 281-286.

5. Zhan, Y.; Zhao, R.; Lei, Y.; Meng, F.; Zhong, J.; Liu, X. A novel carbon nanotubes $/ \mathrm{Fe}_{3} \mathrm{O}_{4}$ inorganic hybrid material: Synthesis, characterization and microwave electromagnetic properties. J. Magn. Magn. Mater. 2011, 323, 1006-1010. [CrossRef]

6. Chen, Y.-H.; Huang, Z.-H.; Lu, M.-M.; Cao, W.-Q.; Yuan, J.; Zhang, D.-Q.; Cao, M.-S. 3D Fe ${ }_{3} \mathrm{O}_{4}$ nanocrystals decorating carbon nanotubes to tune electromagnetic properties and enhance microwave absorption capacity. J. Mater. Chem. A 2015, 3, 12621-12625. [CrossRef]

7. Ran, F.; Yang, H.; Wu, Y.; Zhao, X.; Tan, Y.; Liu, Y.; Niu, X.; Chen, Y.; Kong, L.; Kang, L. Facile preparation of porous nickel oxide membrane for flexible supercapacitors electrode via Phase-separation method of polymer. Mater. Res. Bull. 2018, 103, 25-31. [CrossRef]

8. Atiq, S.; Javid, M.; Riaz, S.; Naseem, S. Magnetic phase transition in nickel oxide. Mater. Today Proc. 2015, 2, 5262-5267. [CrossRef]

9. Chen, J.; Wang, Y.G.; Li, Z.Q.; Wang, C.; Li, J.F.; Gu, Y.J. Synthesis and characterization of magnetic nanocomposites with $\mathrm{Fe}_{3} \mathrm{O}_{4}$ core. J. Phys. Conf. Ser. 2009, 152, 012041. [CrossRef]

10. Eriksson, A.; Deleniv, A.; Gevorgian, S. Resonant tunneling of microwave energy in thin film multilayer metal/dielectric structures. In Proceedings of the 2002 IEEE MTT-S International Microwave Symposium Digest, Seattle, WA, USA, 2-7 June 2002; Volume 7, pp. 2009-2012.

11. Xu, D.; Yang, S.; Chen, P.; Yu, Q.; Xiong, X.-H.; Wang, J. 3D nitrogen-doped porous magnetic graphene foam-supported Ni nanocomposites with superior microwave absorption properties. Alloy. Compd. 2019, 782, 600-610. [CrossRef]

12. Wen, Q.; Zhou, W.; Gao, H.; Zhou, Y.; Luo, F.; Zhu, D.; Huang, Z.; Qing, Y. High dielectric and microwave absorption properties of ultra-thin $1-\mathrm{xSrTiO}_{3}-\delta-\mathrm{xSrAl}_{12} \mathrm{O}_{19}$ films. Ceram. Int. 2018, 11, 12210-12215. [CrossRef]

13. Li, Y.; Cheng, H.; Wang, N.; Zhou, Y.; Li, T. Magnetic and microwave absorption properties of $\mathrm{Fe} / \mathrm{TiO} 2$ nanocomposites prepared by template electrodeposition. J. Alloys Compd. 2018, 763, 421-429. [CrossRef]

14. Emadi, F.; Nemati, A.; Hinterstein, M.; Adabifiroozjaei, E. Microstructural, optical, and electrical characteristics of Ni/C doped BST thin films. Ceram. Int. 2019, 5, 5503-5510. [CrossRef]

15. Chang, K. Encyclopedia of RF and microwave engineering. Encycl. RF Microw. Eng. 2005, 4, 3869-3891.

16. Ibarra-Castanedo, C.; Piau, J.-M.; Guilbert, S.; Avdelidis, N.P.; Genest, M.; Bendada, A.; Maldague, X.P.V. Comparative study of active thermography techniques for the nondestructive evaluation of honeycomb structures. Res. Nondestr. Eval. 2009, 20,1-31. [CrossRef]

17. Xiao, G.; Li, S.; Li, H.; Chen, L. Synthesis of doped ceria with mesoporous flower like morphology and its catalytic performance for CO oxidation. Microporous Mesoporous Mater. 2009, 120, 426-431. [CrossRef]

18. Ramanujan, R.V.; Ong, C.K.; Liu, Z.; Zeng, D.C. Rigid and flexible Fe-Zr-N magnetic thin films for microwave absorber. J. Appl. Phys. 2010, 107, 6573. [CrossRef]

19. Li, J.; Bi, S.; Mei, B.; Shi, F.; Cheng, W.; Su, X.; Hou, G.; Wang, J. Effects of three-dimensional reduced graphene oxide coupled with nickel nanoparticles on the microwave absorption of carbon fiber-based composites. J. Alloys Compd. 2017, 717, 205-213. [CrossRef]

20. Lindner, J.; Barsukov, I.; Raeder, C.; Hassel, C.; Posth, O.; Meckenstock, R.; Landeros, P.; Mills, D.L. Two-magnon damping in thin films in case of canted magnetization: Theory versus experiment. Phys. Rev. B Condens. Matter. 2009, 80, 224421. [CrossRef]

21. Butera, A.; Gómez, J.; Weston, J.L.; Barnard, J.A. Growth and magnetic characterization of epitaxial $\mathrm{Fe}_{81} \mathrm{Ga}_{19} / \mathrm{MgO}(100)$ thin films. J. Appl. Phys. 2005, 98, 33901. [CrossRef] 
22. Jung, A.; Natter, H.; Diebels, S.; Lach, E.; Hempelmann, R. Nanonickel coated aluminum foam for enhanced impact energy absorption. Adv. Eng. Mater. 2011, 13, 23-28. [CrossRef]

23. Wang, J.C.; Zhou, H.; Zhuang, J.D.; Liu, Q. Influence of spatial configurations on electromagnetic interference shielding of ordered mesoporous carbon/ordered mesoporous silica/silica composites. Sci. Rep. 2013, 3, 3252. [CrossRef] [PubMed]

24. Shi, Y.; Zhang, F.; Hu, Y.; Sun, X.; Zhang, Y.; Lee, H.I.; Chen, L.; Stucky, G.D. Low-temperature pseudomorphic transformation of ordered hierarchical macro-mesoporous $\mathrm{SiO}_{2} / \mathrm{C}$ nanocomposite to $\mathrm{SiC}$ via magnesiothermic reduction. J. Am. Chem. Soc. 2010, 41, 5552-5553. [CrossRef] [PubMed]

25. Francoeur, M. Electric and magnetic surface polariton mediated near-field radiative heat transfer between metamaterials made of silicon carbide particles. Opt. Express 2011, 19, 18774-18788. [CrossRef] [PubMed]

26. Liu, Y.B.; Jin, R.; Qiu, J.; Liu, L.H. Spectral radiative properties of a Ni porous microstructure and magnetic polariton resonance for light trapping. Int. J. Heat Mass Transf. 2016, 988, 33-844.

27. Chen, T.; Deng, F.; Zhu, J.; Chen, C.; Sun, G.; Ma, S.; Yang, X. Hexagonal and cubic Ni nanocrystals grown on graphene: Phase-controlled synthesis, characterization and their enhanced microwave absorption properties. J. Mater. Chem. 2012, 22, 15190-15197. [CrossRef]

28. Song, W.-L.; Guan, X.-T.; Fan, L.-Z.; Zhao, Y.-B.; Cao, W.-Q.; Wang, C.-Y.; Cao, M.-S. Strong and thermostable polymeric graphene/silica textile for lightweight practical microwave absorption composites. Carbon 2016, 100, 109-117. [CrossRef]

29. Liu, J.; Xu, J.; Che, R.; Chen, H.; Liu, Z.; Xia, F. Hierarchical magnetic yolk shell microspheres with mixed barium silicate and barium titanium oxide shells for microwave absorption enhancement. J. Mater. Chem. 2012, 22, 9277-9284. [CrossRef]

30. Yusoff, A.N.; Abdullah, M.H.; Ahmad, S.H.; Jusoh, S.F.; Mansor, A.A.; Hamid, S.A.A. Electromagnetic and absorption properties of some microwave absorbers. J. Appl. Phys. 2002, 92, 876-882. [CrossRef]

31. Liu, Z.S.; Shao, G.; Chen, D.L.; Zhang, R. Preparation and characterization of Fe/SiC ceramic-metal composites. Key Eng. Mater. 2010, 434, 66-68. [CrossRef]

32. Vollath, D.; Szabó, D.V.; Haußelt, J. Synthesis and properties of ceramic nanoparticles and nanocomposites. J. Eur. Ceram. Soc. 1997, 17, 1317-1324. [CrossRef]

33. Lieberthal, M.; Kaplan, W.D. Processing and properties of $\mathrm{Al}_{2} \mathrm{O}_{3}$ nanocomposites reinforced with sub-micron $\mathrm{Ni}$ and $\mathrm{NiAl}_{2} \mathrm{O}_{4}$. Mater. Sci. Eng. 2001, 302, 83-91. [CrossRef]

34. Yu, C.; Zhang, L.; Shi, J.; Zhao, J.; Gao, J.; Yan, N. A simple template-Free strategy to synthesize nanoporous manganese and nickel oxides with narrow pore Size distribution, and their electrochemical properties. Adv. Funct. Mater. 2008, 18, 1544-1554. [CrossRef]

35. Wen, B.; Cao, M.; Hou, Z.-L.; Song, W.-L.; Zhang, L.; Lu, M.-M.; Jin, H.-B.; Fang, X.-Y.; Wang, W.-Z.; Yuan, J. Temperature dependent microwave attenuation behavior for carbon-nanotube/silica composites. Carbon 2013, 65, 124-139. [CrossRef]

36. Wang, L.; Guan, Y.; Qiu, X.; Zhu, H.; Pan, S.; Yu, M.; Zhang, Q. Efficient ferrite/Co/porous carbon microwave absorbing material based on ferrite@metal- organic framework. Chem. Eng. J. 2017, 326, 945-955. [CrossRef]

37. Vichaphund, S.; Atong, D. Fabrication of Ni-alumina composite membrane via and bulk impregnation method for hydrogen separation. Mater. Sci. Technol. 2010, 26, 589-596. [CrossRef]

(C) 2020 by the authors. Licensee MDPI, Basel, Switzerland. This article is an open access article distributed under the terms and conditions of the Creative Commons Attribution (CC BY) license (http://creativecommons.org/licenses/by/4.0/). 